\title{
SARS-COV-2/COVID19 Induce Kawasaki-Like Disease in Children Experience of Republic of Moldova: A Report of Five Cases
}

\author{
Ninel Revenco ${ }^{1,2, *}$, Eremciuc Rodica ${ }^{1}$, Foca Silvia ${ }^{2}$, Balanuta Ana- Mihaela ${ }^{1,2}$, Ala Jivalcovschi ${ }^{2}$, Anna Coeva ${ }^{2}$, Bujor Dina $^{1,2}$, Irina \\ Vasilieva $^{1,3}$, Maria Vasilieva ${ }^{1,3}$, Ilie Vasiliev ${ }^{3, *}$ \\ ${ }^{1}$ State University of Medicine and Pharmacy "Nicolae Testemitanu". \\ ${ }^{2}$ Public Healthcare Institution - Mother and Child Institute. \\ ${ }^{3}$ World Academy of Medical Sciences, Netherlands, Republic of Moldova.
}

*Corresponding Author: Ninel Revenco MD, PhD, Professor. Head of Department of Pediatrics, State University of Medicine and Pharmacy, "Nicolae Testemitanu", Republic of Moldova.

*With advisory support: Ilie Vasiliev MD, Professor at the World Academy of Medical Sciences. First Superior Executor Vice- President of the World Academy of Medical Sciences. Chairman of the World Council of the Academy WAMS. WAMS Coronavirus Safety Committee.

Received date: February 24, 2021; Accepted date: March 06, 2021; Published date: March 10,2021

Citation: N Revenco, E Rodica, F Silvia, Balanuta A Mihaela, I Vasiliev, et al. (2021) SARS-COV-2/COVID19 Induce Kawasaki-Like Disease in Children Experience of Republic of Moldova: A Report of Five Cases. Biomedical Research and Clinical Reviews. 3(3); DOI: 10.31579/2692-

9406/055

Copyright:@2021 Ninel Revenco \& Ilie Vasiliev, This is an open-access article distributed under the terms of the Creative Commons Attribution License, which permits unrestricted use, distribution, and reproduction in any medium, provided the original author and source are credited.

\begin{abstract}
:
Infection with SARS-CoV-2 virus is a serious challenge for the entire medical and scientific community. Medical institutions are facing record numbers of patients and conflicting claims about SARS-CoV-2 and due to its mutagenic properties, thanks to the $\mathrm{D} 614 \mathrm{G}$ protein from Coronavirus $(\mathrm{CoV})$ defining the determines the mutagenicity of SARS - CoV and MERS-CoV [1,2]. With the expansion of the COVID-19 Pandemic, researchers have reported [3] clinical cases of multisystemic inflammatory syndrome in children (MIS-C), similar to Kawasaki disease (KD). Due to the absence of a diagnostic marker for KD, the latter is established according to the criteria of the American Society of Cardiology, in this situation with associated SARS-CoV2 infection. We deem it appropriate to report five clinical cases of KD that met the criteria for defining an MIS-C case as defined by WHO
\end{abstract}

Keywords: kawasaki disease; sars-cov-2; multi-systemic inflammatory syndrome; child clinical case

\section{Introduction}

Case reports are valuable resources, essential prerequisites for developing critical thinking based on medical experience. Although the first published studies reported a relatively mild benign course of SARS-CoV2 infection in children, a new presentation of Covid-19 appears in the pediatric population in late April / early May 2020, as childhood MIS-C is temporarily associated with SARS-CoV-2 infection, which has characteristics similar to those of other inflammatory conditions in children, such as KD, staphylococcal and streptococcal toxic shock syndrome, bacterial sepsis, macrophage activation syndrome. It can also manifest itself with excessively high levels of inflammatory markers and abdominal syndrome, which can mimic appendicitis or typhoid fever [4].

It is known that medical studies have identified about 30 different types of vasculitis, the triggering mechanism of which is endothelins generated by genetic [5,6] and immunocompromising (IC) CHAOS [C]ardiovascular Compromise: shock; [H]omeostasis; [A]poptosis; [O]rgan Dysfunction; [S] uppression of the Immune System with the development of SIRS (Systemic inflammatory response syndrome) [7,8],
Multiple Organ Dysfunction Syndrome (MODS), HELLP-syndrome $[\mathrm{H}]$ (Hemolysis) [EL](Elevated liver enzymes) [LP](Low platelet count)] [9-11]. KD is one of the most common acute systemic vasculitides in children, affecting medium-sized arteries, especially coronary arteries; the clinical picture describes an acute onset with high fever, generalized polymorphous exanthema, palmar-plantar erythema, symmetric nonsuppurative conjunctivitis, usually unilateral cervical lymphadenopathy, which lasts about 12 days, and enanthem of the mucous membrane with redness and chapped lips [12].

The etiology, immunology, and pathophysiology of KD are poorly understood, although elements of the immune system play a key role [13]. $\mathrm{KD}$, in both its typical and atypical manifestations, has been described as associated with infectious agents such as Streptococcus pyogenes, Staphylococcus aureus, and Yersinia pseudotuberculosis, as well as with viral infections such as adenoviruses, enteroviruses, Epstein-Barr virus (EBV), and non - SARS-CoV-2 [14,15], and approximately $2 \%$ of children may develop macrophage activation syndrome [16]. 
Scientists have concluded that KD is the leading cause of coronary heart disease in the pediatric population. The most alarming complication of $\mathrm{KD}$ is aneurysmal dilatation of the coronary arteries, which can be detected by echocardiography starting from the 2 nd week of the recovery stage [13]. Recently, several scientific journals have published a series of $\mathrm{KB}$ cases associated with SARS-CoV-2 infection, among which the cases are reported in the Republic of Moldova [3], Great Britain, Italy, France, USA, Turkey [17-22].

Purpose of the study. To provide an overview of the main features of Kawasaki disease and to promote the early recognition, diagnosis, and treatment of KD in our country.

\section{Materials and methods}

This is a single-center, prospective observational study. This case series report describes five pediatric patients with MIS-C who were hospitalized between April 22 and October 9, 2020, at the Institute of Mother and Child of the Republic of Moldova. Variables analyzed included anamnestic data, demographic information, general clinical manifestations, epidemiological data confirming susceptibility to SARSCoV-2 infection, laboratory and imaging studies, and the evolution of the disease by the applied therapeutic tactics.

The MIS-C patients enrolled in the study met the recently revised WHO definition of children and adolescents 0 to 19 years of age with fever $\geq 3$ days, plus 2 of the following: a) Rash or bilateral nonsuppurative conjunctivitis or signs of mucosal inflammation. (oral, hands, feet); b) Hypotension or shock; c) characteristics of myocardial dysfunction, pericarditis, valvulitis, or coronary artery abnormalities, including imaging data (echocardiography) and laboratory tests (elevated troponin and/or NT-proBNP levels); d) Evidence of coagulopathy (eg, increased prothrombin time / INR, time of partially activated thromboplastin, Ddimer levels); e) acute gastrointestinal symptoms (vomiting, diarrhea) or abdominal pain; and Elevated markers of inflammation, such as Erythrocyte sedimentation rate (ESR), C-reactive protein (CRP), or procalcitonin, and absence of other obvious microbial causes of inflammation, including bacterial sepsis, staphylococcal or streptococcal shock syndrome, and Proof of COVID-19 Reverse transcription polymerase chain reaction (RT-PCR), positive serological tests, or possible contact with patients who test positive for COVID-19.

KD was defined according to the criteria of the American Society of Cardiology, including both classic types (fever $\geq$ five days plus four or more of the following clinical criteria: non-exudative bulbar conjunctivitis, lip or oral mucosa changes, non-purulent late cervical lymphadenopathy, erythematous polymorphic skin rash, erythema of the palms or soles, hard induration of the hands or feet, or both for complete disease and fever for $\geq$ five days plus 2 or 3 clinical criteria mentioned for incomplete type).

\section{Results}

The five patients with a diagnosis of MIS-C similar to KD ranged from 8 months to 10 years of age. When considering the gender distribution, the prevalence of women $(80 \%)$ over men $(20 \%)$ was noted.

All patients included in the study had at least one evidence of SARS-CoV2 infection, 2 (40\%) of whom tested positive by RT-PCR in a nasopharyngeal swab. In contrast, the remaining $3(60 \%)$ showed positive serological data for anti-SARS-CoV-2 IgG and IgM. Patients 3 and 5, along with serologic evidence of SARS-CoV-2 infection, also presented serologic evidence of latent EBV infection. Clinical manifestations at admission to the hospital included persistent drug-resistant fever, polymorphic skin rash without blistering or crusts and no itching, signs of peripheral skin inflammation manifested by palmar or plantar erythema, and abdominal pain in $100 \%$ of cases. Four (80\%) out of five patients had non-exudative bulbar conjunctivitis and signs of damage to the oral mucosa manifested as redness and cracked lips, a raspberry tongue with hypertrophied papillae, and diffuse oropharyngeal erythema. Unilateral cervical lymphadenitis occurred in patients 1,2 , and $3(60 \%)$; in inpatient 4 , bilateral cervical lymphadenitis was found, in the fifth, it was not detected. In patients 2 and 5 , at the onset of the disease, clinical manifestations of the digestive system were also observed, expressed in diarrhea and single vomiting.

When analyzing the results of laboratory studies, an increase in the number of reactants of the acute phase of inflammation was revealed in $100 \%$ of cases, which is different for each case. Thus, ESR and hyperfibrinogenemia were recorded in $60 \%$ of cases, while in $100 \%$ of cases, an increase in CRP was observed, the values of which varied from 12 to $96 \mathrm{mg}$. / L. In the early stages of the disease, leukocytosis was present in $80 \%$ of patients, neutrophilia in $60 \%$, lymphopenia and anemia in $80 \%$, which returned to control values during treatment. In $40 \%$ changes in the platelet count showed thrombocytopenia, and in $60 \%$ thrombocytosis, as well as the transition from thrombocytopenia to thrombosis. Other changes were nitrogen retention syndrome, manifested by elevated serum creatinine and urea levels in $40 \%$, increased liver transaminases in $20 \%$, and an increase in the MB level of creatine kinase in $80 \%$. Along with nitrogen retention syndrome, minor proteinuria was also observed, which was negative during therapy with corticosteroids. Echocardiographic studies performed during hospitalization in $80 \%$ of cases did not reveal signs of impaired myocardial contractility, pericardial perfusion, or aneurysmal dilatation of the coronary arteries. The detected changes in the diameter of the coronary arteries during ultrasound examination of the heart were supplemented by angiographic magnetic resonance imaging of the heart to exclude aneurysmal expansion of the heart. The electrocardiogram revealed an extended QT interval. 80\% of patients had typical imaging signs of unilateral or bilateral pneumonia found on chest x-ray, although respiratory symptoms were mild. 


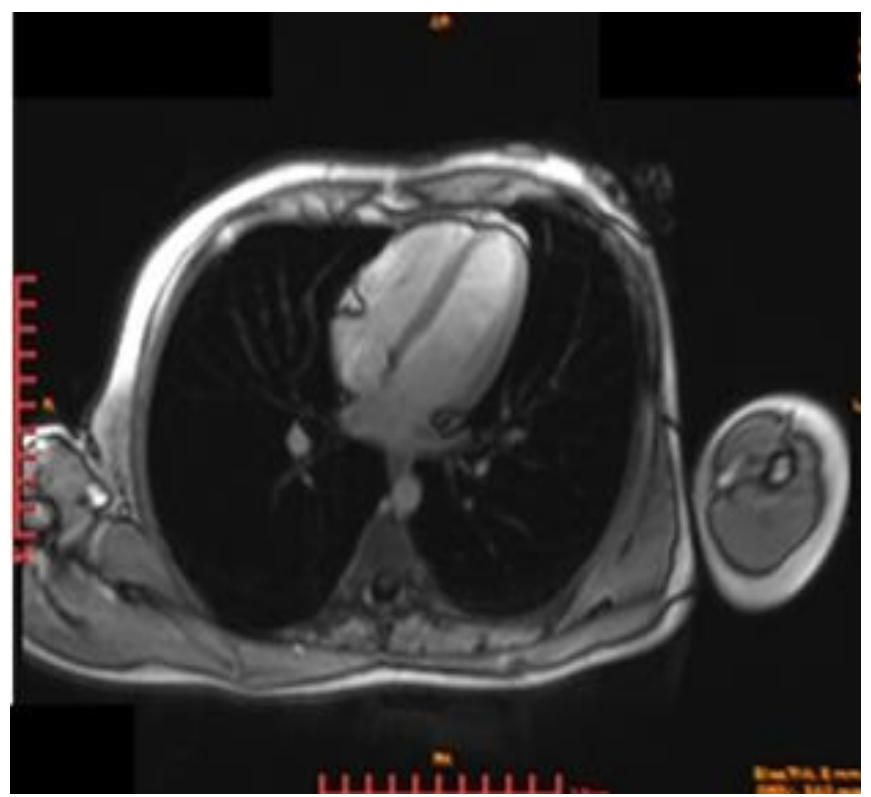

Figure 1: Cardiac magnetic resonance imaging in pediatric patients with MIS-C for SARS-CoV-2 infection. A. 4-camera image of a 10-year-old female patient with normal cardiac appearance.

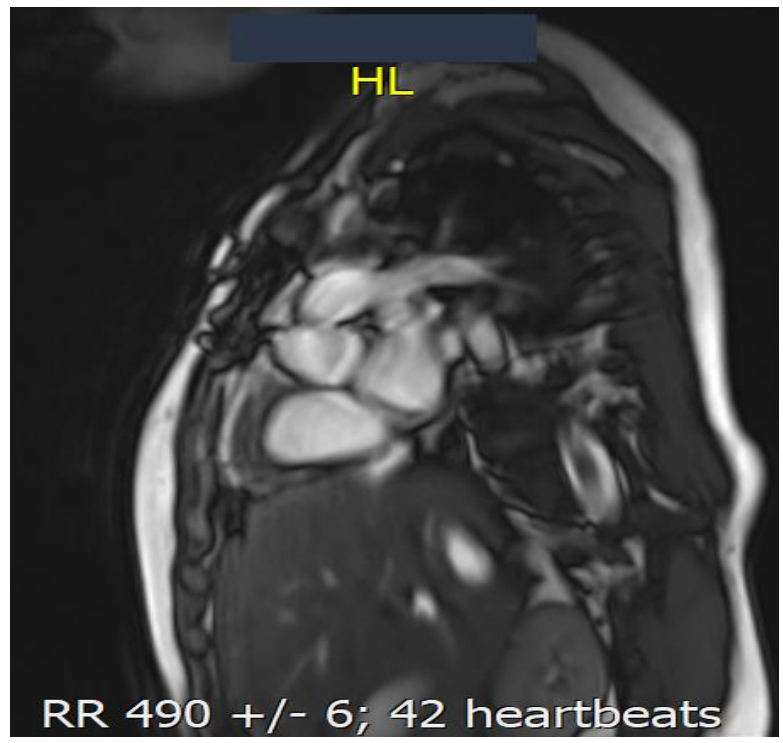

Figure 2: MRI of the heart in a 7-year-old patient. Indistinct diffuse changes in the interstitial space and extracellular volume of the left ventricular myocardium - the appearance of cardiac MRI for mild diffuse interstitial fibrosis, as a manifestation of sustained myocarditis.

All 5 cases required at least 24 hours of observation in the intensive care unit; the second patient also needed oxygen support. Treatment included corticosteroids, antibiotics, antiplatelet drugs, and symptomatic therapy as appropriate. In $100 \%$ of cases, the therapeutic response was positive. The patients were discharged with a recommendation to return later to check the long-term course of the disease and early detection of possible complications specific to KD that may occur remotely. To date, none of the patients included in the study have developed any complications.

\section{Discussions:}

Initially, SARS-CoV-2 infection in children was reported to be mild, with few ICU admissions and very few deaths. Children infected with SARSCoV-2 may develop asymptomatic or may have a fever, respiratory and gastrointestinal symptoms [23]. As of April 2020, in the United Kingdom, scientists have determined that children with persistent fever, elevated acute phase reagents (neutrophilia, elevated PCR, and lymphopenia), one or more organ dysfunction like MIS-C compared to SARS-CoV-2. The phenotypes in this category are typical or atypical KD, KD shock syndrome, toxic shock syndrome, and macrophage activation syndrome (MAS) [24]. In this study, we analyzed only a group of patients who met the criteria for typical or atypical KD associated with COVID-19. The temporal relationship between clinical and paraclinical manifestations of MIS-C and the presence of laboratory evidence of SARS-CoV-2 infection in five children included in our small cohort supports the etiopathogenetic hypothesis that this syndrome is the result of a post-infectious immune response. According to recent reports, childhood MIS-C often begins 16 weeks after SARS CoV-2 infection and may overlap with an acute respiratory manifestation of COVID-19 [24].

In our cohort, the most common clinical manifestations were drugresistant prolonged febrile syndrome and skin syndrome. Fatigue, 
myalgia, arthralgia, headache, often described in adults, were less pronounced in children, which could be explained by their inability or difficulty in reporting them $(60 \%$ of patients included in our study were under five years of age or had difficulty expressing). tongue). Although our patients showed signs and symptoms characteristic of KD, such as fever, rash, changes in the oral mucosa, conjunctivitis, cervical lymphadenopathy, thrombocytosis (in the later stages of the disease), there were some differences from classical KD, such as affecting older children, affecting the respiratory system (confirmed by imaging), gastrointestinal disturbances, lymphopenia and thrombocytopenia, which in some cases progressed to thrombocytosis. KD is a clinical diagnosis and there is currently no specific diagnostic test. It may present atypically as KD shock syndrome and rarely as macrophage activation syndrome. McCrindle BW et al. believe that CD may be a manifestation of a genetic predisposition to an abnormal immune response to some specific infectious agents [25].

Renal failure, expressed by nitrogen retention syndrome and mild proteinuria, registered in patients 2 and 5 , can be explained by the presence of SARS-CoV-2 receptors type ACE 2 in the kidneys. At the same time, these two patients also had clinical manifestations of digestive disorders, expressed by diarrhea and vomiting in patient 2 , which indicates a prerenal lesion. The proposed specific mechanisms of secondary COVID-19 kidney damage are associated with ACE 2 (angiotensin-converting enzyme 2) receptors, which are recognized as SARS-CoV-2 receptors and are located on the surface of epithelial cells in the lungs, heart, and kidneys, gastrointestinal system, testes, basal epidermal cells and hair follicles, and cells of the central nervous system. Thus, the $\mathrm{S} 1$ subunit of the viral protein $\mathrm{S}$ binds to the ACE-2 receptor, activating angiotensin II. Puelles VG et al. argue that co-expression of ACE-2 and TMPRSS2 plays an important role in facilitating entry into the genome [26]. Through viral invasion, SARS-CoV-2 can have a direct cytopathic effect on renal cells [26]. One of the earliest studies to identify kidney damage associated with SARS-CoV-2 infection is the study by DJ Stewart et al. In Great Britain. According to this study, about half of the 52 children hospitalized with COVID-19 showed signs of renal dysfunction, and about a quarter of them met the criteria for acute kidney injury [27]. Along with the ACE-2 pathway, it will also be important to determine and another pathway [28] for the penetration of coronavirus into the cell in children through a molecule, the cluster of protein differentiation (CD147) [also called extracellular matrix metalloproteinase inducers (EMMPRIN) or Basigin (BSG) and belonging to the superfamily immunoglobulins]. As well as the features of the development of Oxidative and Nitro-Halogenic stress in children with SARS-Cov2 / COVID / 19 with the Cyto-destructive effect of membrane lipid peroxidation [28], the syndrome of electro- ionic membrane distress (syndrome of Maria\&Irina Vasilieva) [29-32] and prevalence of SIRS over CARS in successful resuscitation in critically ill adult patients infected with SARS-CoV-2 [1,2,28] with support: respiratory [33], cardiac [34] and cerebral [35-39]. In children, the manifestation of NitroHalogen stress could explain the development of aneurysmal dilatation of the coronary arteries due to the slower action of the antiproliferative effect of NO (reactive nitrogen species, RNS) on the smooth muscle cells of the vascular wall.

Four out of five children included in the study showed signs of myocardial inflammation, expressed by an increased content of creatine phosphokinase $\mathrm{MB}$, and in the fifth patient, driving disorders were also recorded on electrocardiography due to prolongation of the QT interval, which disappeared during the next hospitalization. The pathogenesis of myocardial injury associated with COVID-19 in children is unknown. A recent Chinese study shows that SARS CoV-2 is much less common in children due to lower ACE2 levels than in adults [40]. Cui et al. reported acute myocarditis associated with SARS-CoV-2 infection in a 55-day-old infant who had elevated cardiac troponin levels on admission [41].
Another study describing heart failure in MIS-C is being conducted in the Bronx, NY by Einat B. et al. in a group of 19 children, where 1 out of three patients with signs of heart disease developed ecstatic expansion of the coronary artery [42]. The pediatric patients mentioned in this study will require dynamic monitoring, taking into account the risk of heart damage in the later stages of KD and the unpredictable development of MIS-C.

\section{Conclusions:}

Kawasaki disease in the context of SARS-CoV-2 infection is a new disease in pediatrics; however, knowledge about pathogenic mechanisms, risk factors, and long-term consequences is limited. A multidisciplinary approach is essential for early detection of this nosology and the initiation of correct treatment to prevent long-term complications. It is important to find out if MIS-C in children is a new entity or if SARS-CoV-2 is acting as a new trigger for Kawasaki disease. Further research, as well as case studies from around the world, will help avoid delaying urgent and targeted treatment.

\section{Ethical Approval by Ethical Committee}

It is not applicable.

\section{Competing Interests}

Authors have declared that no competing interests exist

\section{References}

1. Cojocaru V, Ceban E, Vasilieva Maria, Vasilieva Irina, Groppa S, Vasiliev I*, Diug E, Placinta Gh, Condrea D, Guila E, Ginga D, Zatîc T, Diug V, Cebotari S, Tofan-Scutaru L, Valicu V, Frumusachi M, Lipeț L, Istrati V, Matcovschi S, Bacinschi N, Bologa L, Tagadiuc O, Globa P, Holban T, Vudu L, Caradja Gh, Alexa Z, Nacu A, Bețiu M, Afanasiev V, Bogdan V, Sili V, Ganea $\mathrm{N}$ and Tudos S. (2020) Tödliche $\beta$-SARS - Cov-2 COVID 19 ist noch kein Satz. Published on LinkedIn. WAMS.

2. Cojocaru V, Ceban E, Vasilieva Irina, Vasilieva Maria V, Vasiliev I*, Diug E, Placinta Gh, Groppa S, Condrea D, Guila E, Zatic T, Diug V, Cebotari S, Tofan-Scutaru L, Valicu V, Frumusachi M, Lipet L, Istrati V, Matcovschi S, Bacinschi N, Bologa L, Holban T, Vudu L, Karadja G, Nacu A and Bețiu M. (2020) Successful resuscitation of deadly SARS - Cov-2 / COVID19. Bioinformatics \& Proteomics Open Access Journal.

3. Revenco Ninel, Foca S. Jivalcovschi A, Ziaev L, Turea T, Bujor D, Balanuța Ana-Mihaela, Serbenco L, Vasilieva Irina, Vasilieva Maria, Vasiliev Ilie. (2020) Challenges of Pediatric Multisystem Inflammatory Syndrome Associated with Covid-19 - A Series of Clinical Cases. Biomedical Research and Clinical Reviews.1(4): 1-3.

4. Götzinger, Florian Pfefferle, Jasmin et al. COVID-19 in children and adolescents in Europe: a multinational, multicentre cohort study; The Lancet Child \& Adolescent Health, Volume 4(9), 653 661.

5. Irina Vasilieva. (2018) Genetic aspects of addiction. Public Health Chronicle. Journal of the State Public Health Surveillance Service. 1(46):9-10.

6. Vasilieva Irina. (2016) Genetic aspects of addiction (scientific advisory - MD Elena Chesov, associate professor, Dep of Molecular Biology and Human Genetics). Days of the State University of Medicine and Nicolae Testemitanu Pharmacy.

7. Vasiliev I, Vasilieva Maria, Vasilieva Irina, Catereniuc I, Globa T, Nacu V. (2015) The extracorporeal bio-xeno perfuzion (myelotimo-spleen) in multi-organ suportive therapy (MOST) as a modulator of energy, for immuno corection compensatory antiinflamatory respons sindromes, and persistent inflammation, 
imunno supression, catabolism, and multi organ dysfunction. J Anesth Patient Care. 1:1045.

8. Vasiliev I, Vasilieva Maria, Vasilieva Irina, Catereniuc I, Globa Tatiana, Nacu V, Globa P. (2016) Aggressiveness syndrome hyperantiinflammatory immune CHAOS dissonance and extracorporeal myelotimospleen perfusia. Tolyatti Med Counc. 34:64-67.

9. Vasilieva Irina, Vasilieva Maria, Vasiliev I*, Groppa S, Ghicavii V, D' Ambra Mirta, Friptu V, Gladun S, Diug V, Spinei L, Elena G\&Pavel, Vartanov V, Stavrou I, Tarabrin O and Litarczek G. (2019) Role of pCO2 (AV gap) of multi organ dysfunction syndrome. J Biomed Pharm Sci; 2:2.

10. Vasiliev I. (2020) Mitochondrial of critical obstetric situations in the complex multi-organ support therapy reduces pCO2 (AV gap) and the development of the syndrome of acute multi-organ dysfunction. World Academy of Medical Sciences. WAMS' International Medical Research Council (IMREC). J. of Computational Methods in Molecular Design.

11. Vasiliev I, Vasilieva Maria, Vasilieva Irina, Ghicavii V, Litarczek G, Friptu V, Gladun S, Diug V, Vartanov V,Stavrou I, Tarabrin O and D'Ambra Mirta. (2019) The recruitment of microcirculatorymitochondrial of critical obstetric situations in the complex multiorgan support therapy reduces pCO2 (AV gap) and the development of the syndrome of acute MODs. Biochem Mol Biol J. 5:22.

12. Younger DS. (2019) Epidemiology of the Vasculitides. Neurol Clin. 37:201.

13. A Franco, R Touma, Y Song, C Shimizu, AH Tremoulet, JT Kan egaye, et al. (2014) Specificity of regulatory T cells that modulate vascular inflammation Autoimmunity. 47(2): 95-104.

14. Kikuta H, Sakiyama Y, Matsumoto S et al. (1993) Detection of Epstein-Barr virus DNA in cardiac and aortic tissues from chronic, active Epstein-Barr virus infection associated with Kawasaki disease-like coronary artery aneurysms. J Pediatr. 123(1):90-92.

15. Komatsu H, Fujisawa T. (2008) Kawasaki disease and infection. Nihon Rinsho. 66(2):278-282.

16. Chang LY, Lu CY, Shao PL, et al. (2014) Viral infections associated with Kawasaki disease. J Formos Med Assoc. 113:148154.

17. Akca, U.K., Kesici, S., Ozsurekci, Y. et al. (2020) Kawasaki-like disease in children with COVID. Rheumatol Int.40, 2105-2115.

18. Toubiana J, Poirault C, Corsia A, et al. (2020) Kawasaki-like multisystem inflammatory syndrome in children during the covid19 pandemic in Paris, France: prospective observational study.

19. Verdoni L, Mazza A, Gervasoni A et al. (2020) An outbreak of severe Kawasaki-like disease at the Italian epicentre of the SARSCoV-2 epidemic: an observational cohort study. Lancet. 395:1771-1778.

20. Feldstein LR, Rose EB, Horwitz SM et al. (2020) Multisystem inflammatory syndrome in US children and adolescents. N Eng J Med. 383(4):334-346.

21. Davies P, Evans C, Kanthimathinathan HK et al. (2020) Intensive care admissions of children with paediatric inflammatory multisystem syndrome temporally associated with SARS-CoV-2 (PIMS-TS) in the UK: a multicentre observational study. Lancet Child Adolesc Health. 4(9):669-677.

22. Riphagen S, Gomez X, Gonzalez-Martinez C et al. (2020) Hyperinflammatory shock in children during COVID pandemic. Lancet. 395(10237):1607-1608.

23. Castagnoli R, Votto M, Licari A, et al. (2020) Severe acute respiratory syndrome coronavirus 2 (SARS-CoV-2) infection in children and adolescents: a systematic review. JAMA Pediatr.
24. WHO. Multisystem inflammatory syndrome in children and adolescents with COVID-19.

25. McCrindle BW, Rowley AH, Newburger JW, et al. (2017) Diagnosis, treatment, and long-term management of Kawasaki disease: a scientific statement for health professionals from the American Heart Association. Circulation. 135(17): 927999.

26. Puelles VG, Lütgehetmann M, Lindenmeyer MT. (2020) Multiorgan and renal tropism of SARS-CoV-2. N Eng J Med.

27. Stewart DJ, Hartley JC, Johnson M, Marks SD, du Pré P, Stojanovic J. (2020) Renal dysfunction in hospitalised children with COVID-19. Lancet Child Adolesc Health. 4(8):28-29.

28. Vasilieva Maria, Vasilieva Irina, Vasiliev I*, Groppa S, Ghidirim Gh, Bețiu M, Diug Valentina, Bacinschi N, Diug E, Tagadiuc O, Globa Pavel\&Tanea, Revenco Ninel, Plăcintă Gh, Vudu L, Bernic Jana, Caradja Gh, Globa Lilian\&Elena, Ignatenco S, Serbenco L, Cealan A, Mirta D'Ambra, Tarabrin O. (2020) Intralipid in the Treatment of Lipid Peroxidation Disorder Caused by Oxidative and Nitro - Galogenic Stress in Patients with SARSCov2/COVID19. J of Advances in Medical and Pharmaceutical Sciences. 22(11); 20-30.

29. Vasilieva Maria, Vasilieva Irina, Vasiliev I*, Malakhova M, Groppa S, Ghidirim Gh, Tofan-Scutaru L, Vanevsky P, Gavriliuk M, Moldovanu I, Globa Tatiana, Iavorschi C, Revenco Ninel, Mirta D'Ambra, Globa P, Visnevschi A, Globa Elena, Spinei Larisa, Katereniuk I, Caradja Gh, Nacu V, Bacinschi N, Dumitraş V, Rotaru N, Diug Valentina, Ignatenco S, Stoleriu Gabriela, Stavrou I, Vartanov V, Litarczek G. (2020) L'importance du Sindrom Maria\&Irina Vasilieva (syndrome de détresse de la membrane électro-ionique) dans le développement du syndrome CFS/ME. Published on LinkedIn. WAMS.

30. Vasilieva Maria, Vasilieva Irina, Vasiliev I, Malakhova M, Groppa S, Tofan-Scutaru L, Vanevsky P, Gavriliuk M, Moldovanu I, Globa Tatyana, Revenco Ninel, Mirta D'Ambra, Globa P, Visnevschi A, Globa Elena, Spinei Larisa, Katereniuk I, Karadja Gh, Naku V, Diug V, Stoleriu Gabriela, Stavrou I, Vartanov V, Litarczek G. (2019) Electro-Ion Membrane Distress Syndrome induces Chronic Fatigue Syndrome/Myalgic Encephalomyelitis (CFS/ME). J Clin Res Anesthesiol. 2:1:1.

31. Vasilieva Irina, Vasilieva Maria, Vasiliev I, Malakhova M, Groppa S, Ghidirim Gh, Tofan-Scutaru L, Diug Valentina, Vanevsky P, Gavriliuk M, Moldovanu I, Globa Tatiana, Iavorschi C, Revenco Ninel, Mirta D'Ambra, Globa P, Visnevschi A, Bujor P, Globa, Elena, Spinei Larisa, Catereniuc I, Caradja Gh, Nacu V, Bacinschi N, Dumitraș V, Rotaru N, Vovc V, Stoleriu Gabriela, Globa L, Stavrou I, Vartanov I, Litarczek G. E-Poster. (2020) Maria \& Irina Vasilieva Syndrome Contributes to the manifestation of Chronic Fatigue Syndrome/ Myalgic Encephalomyelitis Syndrome (CFS / ME). National Congress of UroGynecology. "Vasile Dobrovici" Medical Days - November 26-28 - exclusively online. Iași. Romania.

32. Vasilieva Maria, Vasilieva Irina, Vasiliev I*, Malakhova M, Groppa S, Ghidirim Gh, Tofan-Scutaru L, Vanevsky P, P.Bujor3, Gavriliuk M, Moldovanu I, Globa Tatiana, Iavorschi C, Revenco Ninel, Tsypin A, Mirta D'Ambra, Globa P, Visnevschi A, Globa Elena, Spinei Larisa, Katereniuk I, Caradja Gh, Nacu V, Bacinschi N, Dumitraș V, Rotaru N, Diug Valentina,Vove V, Stoleriu Gabriela, Globa L, Stavrou I, Vartanov V, Litarczek G. (2020) Papel Sindrom Maria e Irina Vasilieva en el desarrollo del Síndrome de Fatiga Crónica / Encefalomielitis Mialgica (SFC / EM). Published on LinkedIn. WAMS.

33. Vasiliev I. (2009) Respiratory Support with Alveolar Recruitment for Complex Treatment of Acute Lung Injury and Acute 
Respiratory Distress Syndrome. Krasnoyarsk: International Congress for Respiratory Support.2-7.

34. Vasilieva Irina, Vasilieva Maria, I. Vasiliev, V. Ghicavii, M. Popovici, S. Matcovschi, L. Groppa, G. Litarczek, V. Vartanov, I. Stavrou, D.Ambra Mirta. (2018) Triphosphoric acid, donated, restores heart rhythm disturbances caused by energetically deficient, mitochondrial hypercalcaemia to $\mathrm{Ca}++$ mpt pore lesion. J Clin Res Anesthesiol. 1:1-3.

35. Vasilieva Maria, Vasilieva Irina, Vasiliev I, Groppa S, Ghicavîi V, Moldovanu I, Litarczek G, Vartanov V, Stavrou I, D’Ambra Mirta. (2018) Neurovegetative correction of diencephalichyperkinetic, catabolic adrenergic syndrome. J Clin Res Anesthesiol. 1:1-3.

36. Vasilieva Maria. (2018) Altered State of Consciousness as a Possible Factor to Amplify the Therapeutic Effect in the Case of Neurostimulation in the Chronic Pain. Chisinau: Scientific Adviser MD, PhD Ion Moldovanu Professor, Department of Neurology Nicolae Testemitanu State University of Medicine and Pharmacy of the Republic of Moldova Association of Medical Students and Residents Abstract Book MedEspera 2018 The 7th International Medical Congress for Students and Young Doctors May 3-5, Universul"; 56.

37. D'Ambra M, Vasiliev I, Karindas M. (2019) Small brain vessels disease. Biomed J Sci Technol Res; 19:14555-14556.
38. Vasilieva Maria, Rîbac Nicolae, Țurcanu Vitalie. (2017) Strokes in young children, clinical case (scientific advisory - MD Cornelia Călcîi, associate professor, Department of Pediatrics). "Nicolae Testemitanu" State University of Medicine and Pharmacy. The annual scientific conference, dedicated to the 90th anniversary of the birth of the illustrious Professor and scientist Nicolae Testemitanu. 16-20.

39. Vasilieva Maria. (2018) Altered State of Consciousness as a Possible Factor to Amplify the Therapeutic Effect in the Case of Neurostimulation in the Chronic Pain. Chisinau: Scientific Adviser MD, PhD, Professor, Department of Neurology Nicolae Testemitanu State University of Medicine and Pharmacy of the Republic of Moldova Association of Medical Students and Residents Abstract Book MedEspera 2018 The 7th International Medical Congress for Students and Young Doctors May 3-5, Universul".

40. Dong Y, Mo X, Hu Y, et al. (2020) Epidemiology of COVID-19 among children in China. Pediatrics.

41. Cui Y, Tian M, Huang D, et al. (2020) A 55-day-old female infant infected with 2019 novel coronavirus disease: presenting with pneumonia, liver injury, and heart damage. J Infect Dis. 221:17751781.

42. Einat Blumfield and Terry L. Levin. (2020) COVID-19 in pediatric patients: a case series from the Bronx, NY; Pediatr Radiol. 1-6.

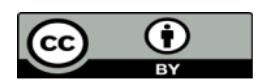

This work is licensed under Creative Commons Attribution 4.0 License

To Submit Your Article Click Here: Submit Manuscript

DOI: $10.31579 / 2692-9406 / 055$
Ready to submit your research? Choose Auctores and benefit from:

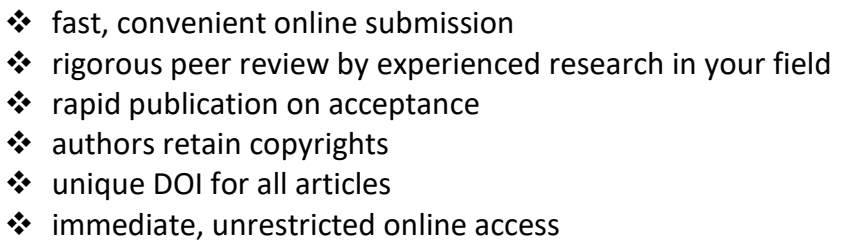

At Auctores, research is always in progress.

Learn more www.auctoresonline.org/journals/biomedical-research-andclinical-reviews- 